TALIA DIXIT $16(2021)$ 59-83

\title{
LOS ANALES CORDUBENSES Y LA HISTORIOGRAFÍA BREVE ANDALUZA DE LA BAJA EDAD MEDIA
}

\author{
THE ANALES CORDUBENSES AND THE ANDALUSIAN BRIEF \\ HISTORIOGRAPHY IN THE LATE MIDDLE AGES
}

\author{
Carmen Benítez Guerrero \& \\ Covadonga Valdaliso Casanova
}

\begin{abstract}
Resumen: Aunque tradicionalmente los anales se han considerado un modo de escritura historiográfica característico de la Alta Edad Media y en decadencia al menos desde el siglo XIII, se conservan numerosos testimonios que prueban que las series analísticas - esto es, los listados de registros historiográficos concisos ordenados cronológicamente- se copiaron, corrigieron, completaron y continuaron, actualizándolos, en los siglos XV y XVI. En este trabajo se estudia un listado analístico copiado en el siglo XV, pero compuesto con anterioridad, que recorre la historia de la Corona de Castilla prestando especial atención a la llamada Reconquista. Sus contenidos, como trataremos de mostrar, están directamente relacionados con otros textos del mismo tipo redactados en Andalucía en la primera mitad del siglo XIV, así como con composiciones similares más tardías.
\end{abstract}

Abstract: Although traditionally it was considered that the annals were the form of historical writing in the Early Middle Ages and fell into decline in the thirteenth century, several witnesses prove that the series of annals - i.e., series of concise historical records arranged chronologically were copied, corrected, expanded, and continued, bringing it up to date, in the fifteenth and sixteenth centuries. This article comprises a study of a series of annals copied in the fifteenth century, but composed before, that cover the history of the Castilian Crown, focusing especially on the so-called Reconquest. As we will try to show, its contents are closely related to other annals written in Andalusia in the first half of the fourteenth century, as well as to later similar compositions.

Palabras clave: Historiografía breve; anales; Andalucía; frontera; Baja Edad Media. Keywords: Brief Historiography; Annals; Andalusia; Frontier; Late Middle Ages

Fecha de recepción: 3 de octubre de 2021

Fecha de aceptación: 25 de octubre de 2021 


\section{Introducción. El 'Cronicón cordubense’ cuatrocentista '}

$\mathrm{D}$ esde fines del siglo XIX viene denominándose Cronicón cordubense a un texto copiado en 1433 por encargo de Diego de Anaya y hoy conservado en la Biblioteca General Histórica de la Universidad de Salamanca. ${ }^{1}$ El nombre le fue dado por Ramón Menéndez Pidal cuando describió el códice que lo contiene en su catálogo de las Crónicas generales conservadas en la biblioteca del Palacio Real de Madrid. ${ }^{2}$ Varias décadas más tarde Derek Lomax llamaría la atención sobre este texto y no mucho después lo publicaría, analizando sus contenidos y cotejándolos con otros escritos del periodo. ${ }^{3}$ Desde entonces el Cronicón cordubense ha sido repetidamente consultado y citado, valorándose tanto sus dataciones de ciertos acontecimientos como el hecho de que algunas de sus entradas registren sucesos no documentados en otros escritos. Con todo, se ha prestado menos atención a algunas consideraciones sobre la redacción, su fecha y sus posibles precedentes que Lomax expuso en el estudio preliminar, y que condicionan bastante la interpretación del texto. A ello se suma que el título dado a la edición-"El Cronicón Cordubense de Fernando de Salmerón”- ha dado pie a bastantes equívocos, pues parece asociar el escrito con el nombre de un autor que no debió serlo.

El manuscrito salmantino consta de dos partes: la segunda, que ocupa los sesenta y tres últimos folios, transmite una novela moral tras la que se anotaron algunas recetas, ${ }^{4}$ mientras la primera consta de ciento doce folios en los que se copiaron una sección de los Bocados de oro, la Historia de

\footnotetext{
Este trabajo se ha desarrollado en el marco de un Contrato de acceso al Sistema Español de Ciencia, Tecnología e Innovación para el desarrollo del programa propio de I+D+i de la Universidad de Sevilla (VPPI2016-II.5), del grupo de investigación HUM-214 de la misma Universidad, y de un proyecto financiado por la FCT_Fundação para a Ciência e a Tecnologia, I.P._ en el ámbito de la Norma Transitória DL57/2016/CP1443/CT0001.

${ }^{1}$ Biblioteca General Histórica de la Universidad de Salamanca, ms. 1866.

${ }^{2}$ Aunque en la tercera y más citada edición (Menéndez Pidal 1918: 221-222) se añadieron en la descripción del volumen algunas indicaciones que no aparecían en la primera (Menéndez Pidal 1898: 147-148) lo referente al Cronicón permaneció igual, y en ambos casos incluido dentro de la sección de "Sumarios de Historia general de España” (Menéndez Pidal 1898: 130-131 y Menéndez Pidal 1918: 203-204). La presencia de este volumen en el catálogo se debe a que estuvo en la biblioteca del Palacio desde fines del siglo XVIII hasta 1954, fecha en que regresó a Salamanca.

${ }^{3} \operatorname{Lomax}$ (1978: 271-273) y Lomax (1982: 595-641).

${ }^{4}$ Véanse Satorre (1980) y Vázquez Janeiro (1996).
} 
la doncella Teodor, el Cronicón cordubense y el decreto del Concilio de Constanza. ${ }^{5}$ Casi todos los textos de esa primera parte fueron escritos por una única mano, que dio por finalizada su tarea introduciendo un colofón en la primera columna del recto del folio $112:^{6}$

Este libro fue acabado miércoles, cuatro días de febrero, año de mil e cuatrocientos e treinta e tres años, estando mi señor don Diego de Anaya, arzobispo de Sevilla, en la muy noble cibdat de Córdoba. E yo, Fernando de Salmerón, lo escreví por su mandado.

De ello se deduce que la copia-y no la redacción-del Cronicón se llevó a cabo en Córdoba a principios del año 1433 en el entorno del arzobispo de Sevilla, Diego de Anaya. Del amanuense, Fernando de Salmerón, sabemos apenas que cuatro años más tarde el arzobispo lo nombrará en su testamento, legándole una cantidad bastante generosa para "ayuda al estudio" y haciendo referencia a un beneficio que tal vez se destinaba a garantizarle una carrera eclesiástica. ${ }^{7}$ Dado que Anaya parece haber confiado la copia de varias de las obras que integraron su biblioteca a personas de su círculo más cercano, podemos especular con la idea de que Fernando de Salmerón fuese un joven discípulo suyo, que le acompañó en un viaje a Córdoba y a quien encomendó trasladar estos textos. ${ }^{8}$ Lomax ya señaló en su día que lo más probable es que su cometido fuese simplemente ese, mientras el Cronicón se habría redactado unos años antes, hacia 141920, posiblemente en la misma Córdoba y a partir de textos preexistentes que documentaban varias etapas de transmisión. ${ }^{9}$

Observado desde esta perspectiva, el Cordubense pasaba a ser una composición anónima escrita, a juicio de Lomax, por un clérigo de la ciudad que habría vivido a caballo entre los siglos XIV y XV, viajado para visitar diferentes bibliotecas, mantenido buenas relaciones con las órdenes militares y mostrado cierta antipatía por Gutierre Álvarez de Toledo-

\footnotetext{
${ }^{5}$ Además de los ya mencionados Menéndez Pidal (1898: 147-148 y 1918: 221-222) y Lomax (1982: 596597), numerosos autores han descrito el manuscrito. Véase también Philobiblon BETA manid 1386.

${ }^{6}$ Posteriormente se añadió una entrada más en la segunda columna y en el verso fue copiado el decreto.

${ }^{7}$ El testamento indicaba que se le concediesen "tres mil maravedís en esta guisa: que si nos fináremos antes que el dicho Fernando haya de nos beneficio, que le den los dichos tres mil maravedís; y si antes que nos fináremos diéremos al dicho Fernando algún beneficio e lo oviere pacífico, que le den mil maravedís pa (sic) ayuda al estudio" (Roxas y Contreras: 238). Sobre este testamento véase Lahoz (2015: 291-300).

${ }^{8}$ Véase sobre ello Jiménez López (2021: 68 y 69). El mismo Salmerón habría copiado en fechas cercanas otro manuscrito, también conservado en la Biblioteca General Histórica de la Universidad de Salamanca (ms. 2011). Sobre este códice véase Bautista (2020).

${ }^{9}$ Sobre todo ello véase Lomax (1982: 605-609).
} 
arcediano de Guadalajara y futuro obispo de Palencia, y arzobispo de Sevilla y Toledo-, dado que registró su detención tras ser acusado de envenenar al obispo de Sigüenza. ${ }^{10} \mathrm{Al}$ analizar el texto, Lomax distinguió una sección que remitía a la época antigua y otra que comenzaba con la entrada de los musulmanes en la Península. A su juicio, la segunda tendría como temática principal la lucha de los cristianos con los musulmanes en el contexto ibérico y pudo estar parcialmente basada en textos historiográficos bien conocidos, pero contendría informaciones procedentes de fuentes no identificadas, lo que demostraba "cómo pequeños cronicones o series de anales podían circular todavía por la España, llamada prerrenacentista, de Ayala y Cartagena, y ser copiados y recopilados por aficionados al pasado". ${ }^{11}$ De esas "series de anales" nos ocuparemos en este trabajo.

Además del que existe en Salamanca se conservan al menos otros dos testimonios del Cronicón cordubense que Derek Lomax no debió conocer. ${ }^{12}$ Los finales son diferentes, siendo el salmantino el único manuscrito que registra el concilio de Constanza, la muerte de la reina Catalina de Lancáster y la mayoría de edad de Juan II, mientras los otros continúan con noticias que avanzan velozmente hasta el reinado de los Católicos. Las diferencias entre el testimonio de Salamanca y los otros dos no se limitan a la parte final, pues los últimos omiten más de una veintena de los registros del primero. ${ }^{13}$ Atendiendo a todo ello, puede presuponerse que existió una composición, que incluía ya las dos secciones mencionadas, de la que habrían derivado tanto la copia de Salmerón como las otras, más tardías, en las que el escrito se alargaba para cubrir las siguientes décadas del siglo XV. Dicha composición se cerraría con la noticia de la muerte de Fernando de Antequera, por lo que su datación post quem sería $1416 .{ }^{14}$

Aunque fue el colofón de Salmerón que fechaba la copia lo que llevó a Menéndez Pidal a denominar "cordubense" a este texto, basándose en sus contenidos Lomax dedujo que debió componerse de hecho en el reino de Córdoba. En favor de ese "fuerte cordobesismo que transpira el Cronicón",

\footnotetext{
${ }^{10}$ Sobre este episodio véase Nieto Soria (2007).

${ }^{11}$ Lomax (1982: 608-609).

${ }^{12}$ En la Biblioteca Nacional de España (MSS/9436, fols. 203r-206v) y en la Real Biblioteca del Monasterio de El Escorial (en adelante RBME), X.II.23, fols. 205r-216v.

${ }^{13}$ De acuerdo con la edición de Lomax (1982) serían las entradas 21, 67 a 75, 81, 83 a 88, 119, 130 y 138.

${ }^{14}$ Es posible que fuese Fernando de Salmerón quien sumó esas tres últimas entradas, que referían un acontecimiento en el que el arzobispo Diego de Anaya había participado y dos sucesos que marcaban el fin de una etapa y el inicio de aquella que constituía su presente, actualizando así el texto.
} 
en palabras del editor, ${ }^{15}$ estarían las entradas que mencionan la ciudad y el hecho de que en algunas de las últimas parezca insinuarse que fue allí en donde se redactaron. Junto con ellas, en esos últimos registros hay también referencias a acontecimientos que tuvieron lugar en la frontera o se relacionaban con episodios de las guerras con Portugal que parecen llevar casi constantemente la atención hacia los territorios meridionales de la Corona. El compilador de 1416 pudo ser, por tanto, un cordobés que redactó o reescribió las entradas que hacían referencia a su tiempo. Sin embargo, la hipótesis de que fuese un clérigo no parece tan sostenible, pues Lomax la basaba en la idea de que ese compilador debió visitar numerosas bibliotecas eclesiásticas. ${ }^{16}$ Creemos que, en realidad, su labor no consistió en componer un listado a partir de noticias extraídas de fuentes muy diversas, sino en actualizar un texto preexistente.

\section{Un posible antepasado: los anales cordubenses}

En un trabajo anterior han sido señalados los claros paralelismos entre el Cronicón cordubense y otros dos textos de tipo analístico compuestos en el siglo XV: el Sumario de las cosas que pasaron en los tiempos pasados y los Anales de Garci Sánchez. ${ }^{17}$ Cuando se colocan lado a lado los tres escritos se identifican con facilidad las coincidencias, de tal modo que gran parte de las entradas anteriores al reinado de Pedro I parecen remitir a un tronco común. Investigaciones posteriores han revelado la existencia de al menos tres composiciones de tipo analístico que se acercan bastante a ese eje estructural, y que presumiblemente se compusieron mucho antes que el Cronicón. La primera de ellas, los Anales del infante (en adelante $A I$ ), es un listado analístico que abarca desde el nacimiento de Jesucristo hasta el desastre de la Vega de Granada en 1319. Solo se conserva en copias modernas, aunque probablemente se compuso en la minoría de Alfonso XI,

\footnotetext{
${ }^{15} \operatorname{Lomax}(1982: 607)$.

16 "No solamente leyó las crónicas oficiales de la monarquía [...] sino que consultó otras obras conservadas en las bibliotecas de Toledo y posiblemente en las de Cardeña, Santiago y Burgos, además de cronicones de las órdenes militares, que se encontrarían, es de suponer, en Uclés, y quizá en Alcántara” (Lomax, 1982: 607 y 608).

${ }^{17}$ Valdaliso Casanova (2021).
} 
tal vez en Córdoba. ${ }^{18}$ El Libro de las eras, por su parte, es un registro de finales del mismo reinado que comparte algunas entradas con los anteriores y tiene otras en común con series procedentes de tradiciones castellanas. De este listado, que comienza con la noticia del nacimiento de Jesucristo y finaliza con la de la conquista de Algeciras, conocemos apenas una copia del siglo XVI. ${ }^{19}$

El tercero de estos escritos, en el que nos centraremos en este trabajo, está claramente emparentado con los que acabamos de mencionar. Es muy probable que se compusiese también en época de Alfonso XI, o no mucho más tarde, pero la única copia que conocemos está incompleta y ello impide saber cuáles eran los últimos acontecimientos que registraba. En todo caso, la datación a partir de la era hispánica en principio indicaría que su composición no fue posterior al reinado de Juan $\mathrm{I}^{20} \mathrm{Si}$ la contemplamos como una narración construida a partir de registros de sucesos ordenados cronológicamente, esta serie analística puede sintetizarse en algunas líneas. Tras una breve introducción, que refiere el nacimiento y la muerte de Cristo, el bautismo de Constantino y el inicio del islam, se registran la invasión musulmana, el comienzo del reinado de Pelayo en Asturias, la presunta visita de Carlomagno a la corte del rey Galafre de Toledo, la construcción de la mezquita y el puente de Córdoba, y el supuesto inicio de la orden de Santiago en tiempos de Ramiro I. La siguiente noticia da un salto de más de un siglo, pues lleva hasta la toma de Toledo. A partir de ahí, y a lo largo de cuarenta entradas, en el escrito se enumeran conquistas, repoblaciones y, en menor medida, algunos otros acontecimientos, como nacimientos y muertes de reyes, hambrunas, eclipses e inundaciones. La noticia más tardía que registra esta copia truncada es la de la batalla de El Salado (1340), aunque no está posicionada en último lugar. ${ }^{21}$

La primera parte del Cronicón cordubense-las cincuenta y cinco primeras entradas, de acuerdo con la numeración establecida por Derek

\footnotetext{
${ }^{18}$ Benítez Guerrero y Valdaliso Casanova (en prensa). Se citará el texto siguiendo la edición que acompaña a este trabajo, indicando el número de la entrada entre corchetes.

${ }^{19}$ RBME, X-II-12, fol. 102r-108r.

${ }^{20}$ Más información sobre el posible contenido de la entrada se hallará en la edición del texto.

${ }^{21}$ Después de la noticia sobre el desastre de la Vega de Granada en 1319, última que registran los $A I$, nuestro texto incorpora cuatro noticias desordenadas cronológicamente (la muerte del "infante Picazo" en 1339; el Salado en 1340; la muerte del infante don Felipe y la ida de Alfonso XI a Sevilla en 1337; y la entrada trunca que habla de la toma de Olvera en 1338). Todas encuentran ciertos paralelismos en el $L E$ (RBME, X.II.12, f.105r-v) y el Cordubense (Lomax, 1982: 631), como podrá observarse en la edición.
} 
Lomax en su edición - se ocupa de episodios de la Antigüedad, casi todos relacionados con los inicios del cristianismo. Tanto el listado del que hablamos como los $A I$, en cambio, comienzan con las mencionadas referencias al nacimiento y la muerte de Jesucristo. Dejando de lado estas dos primeras entradas, casi todas las demás tienen una directa correspondencia con entradas del Cronicón, lo que resulta un claro indicativo de la existencia de una relación entre las composiciones. Sin embargo, las correspondencias raramente son exactas, incluso teniendo en cuenta las variantes de las copias. Además, hay seis entradas del listado que no aparecen en el Cronicón y sí en los $A I$, dos que los $A I$ comparten apenas con el Cronicón, y varias que aparecen exclusivamente o en los $A I$ o en el Cronicón. De todo ello se deduce que debió existir una composición, probablemente de la primera mitad del siglo XIV, que sirvió de base tanto para esta sección del Cronicón como para las otras dos composiciones. Atendiendo a las entradas referentes a Córdoba que comparten todos estos textos, y a la hipótesis en su día formulada por Derek Lomax, llamaremos a ese escrito anales cordubenses.

Como se ha indicado, el listado comparte un amplio número de entradas con los $A I$, composición prácticamente paralela ya desde su comienzo común, con la referencia al nacimiento de Jesucristo. No obstante, algunas diferencias tanto estructurales como de contenido permiten concluir que no se trata de una mera copia con variantes. En primer lugar, porque ambos presentan elementos ausentes en el otro, pero que tienen a su vez reflejo en otros textos. Los $A I$ llevan una serie de entradas que no se encuentran en el texto que aquí nos ocupa: entre otras, que se comentarán más adelante, pueden mencionarse la conquista de Cuenca, la conquista de Damiata por Luis IX en la séptima cruzada, la conquista de Salé, ${ }^{22}$ la entrada de Alfonso X en la Vega de Granada o el magnicidio de Alfaro. En el sentido inverso, este texto hace referencia a las conquistas de Úbeda, Bilches y Baños en la entrada sobre las Navas de Tolosa [17] e incorpora las conquistas de Baena, Luque, Osuna, Palma y Marchena [29]. Estos elementos, que lo separan de los $A I$, lo acercan sin embargo al Cronicón cordubense, y en el primero de los casos también al Libro de las

${ }^{22}$ Acaso por considerarla una duplicación con respecto a la conquista de Cádiz, pues la tradición manuscrita de los $A I$ y del Cordubense habla de Cáliz, $A I$ [48], o Calez según edita Lomax (1982: 628 [97]). El $L E$ recoge Calé, RBME, X.II.12, f.104r. 
eras. ${ }^{23}$ Algo parecido ocurre con la entrada [27] referente al eclipse de 1239 —aquí mal fechado en 1236-, que se refiere también a la conquista de Jerusalén y a la de Ovejo por el concejo de Córdoba. ${ }^{24}$

Las diferencias entre este escrito y los $A I$ resultan evidentes en las entradas inmediatamente anteriores al desastre de la Vega de Granada, enfrentamiento militar en el que murieron los infantes don Pedro y don Juan en 1319-como se ha dicho, la última información consignada por los $A I-$. Así, la noticia sobre la conquista de Alcaudete, que se incorpora después de la entrada común referente a la conquista de Tempul, se atribuye al rey Fernando IV, mientras que los $A I$ la presentan como obra del infante don Pedro. ${ }^{25}$ A partir de aquí, estos últimos recogen las conquistas de Rute, Alicum, Bélmez, Benaxixar, Tíscar, Alhábar y Cambil por parte del infante, ${ }^{26}$ de las cuales solo las dos últimas aparecen en el texto que aquí estudiamos, en una entrada donde la información se suma a la muerte de don Pedro y don Juan en la Vega de Granada [48]. ${ }^{27}$

Como se observa a partir de las noticias analizadas y de las informaciones complementarias aportadas en nota, parece claro que tanto los tres textos que hemos localizado en el reinado de Alfonso XI-aunque algunos presenten intervenciones posteriores resultado de su tradición posterior-, como el Cronicón cordubense publicado por Lomax, trabajan sobre una misma serie analística que funciona como base común, y que en

\footnotetext{
${ }^{23}$ Compárese la entrada [19] con Lomax (1982: 622 [78]) y LE, RBME, X.II.12, f. 103v. Ambos textos mencionan también Tolosa, ausente en Z.III.3, pero las Eras omite Bilches. Para la entrada [29] véase Lomax (1982: 627 [92]).

${ }^{24} \mathrm{La}$ entrada se acerca de nuevo al Cordubense, que sin embargo ha optado por eludir la información del eclipse, y que fecha la entrada en 1237, Lomax (1982: 626 [90]). Los $A I$, por el contrario, omiten la conquista de Jerusalén, e incorporan una entrada sobre la sucesión de Alfonso VIII que llega hasta Alfonso XI entre el eclipse y la conquista de Ovejo, $A I$ [33 a 35]. El $L E$ recoge únicamente el eclipse, fechado correctamente en 1239, al igual que en los $A I$, RBME, X.II.12, f. $104 \mathrm{r}$.

${ }^{25} A I$ [63]. También atribuye la conquista de Alcaudete a Fernando IV el $L E$ (RBME, X.II.12, f.105r), y lo despersonaliza el Cordubense, Lomax, 1982: 630 [109]. En la misma línea se muestran los registros paralelos del XV ya mencionados, el Sumario y los Anales de Garci Sánchez. A pesar de ello, no puede descartarse la posibilidad de que estuviesen transmitiendo el texto en un estado previo a la modificación que comparten los otros tres registros. La crónica del monarca recoge en efecto la conquista por parte del infante, Benítez (2017: 167). Sobre las variantes relacionadas con la cronología véase la nota correspondiente a esta entrada en la edición.

${ }^{26} A I[65,66,67,68]$.

${ }^{27}$ Además de estas dos, también aparecen las conquistas de Rute y Alicum por el infante en el $L E$ (RBME, X.II.12, f.105r). Véase igualmente Lomax (1982: 630, nota 97).
} 
cada caso se orienta en una dirección determinada. ${ }^{28}$ Por ejemplo, el texto de los $A I$ parece haber adaptado esta serie analística para destacar el papel del infante don Pedro en las luchas fronterizas, mientras que en el Libro de las eras - que también se basó parcialmente en esa serie, pero como dijimos muestra una conexión mucho más clara con anales castellanos previos-, resulta claro el interés por subrayar la presencia de Sevilla y la importancia de la conquista de Algeciras. Nuestro listado resulta, sin embargo, más difícil de ubicar e interpretar, pues, como se comentó, la copia se encuentra trunca. Ello imposibilita determinar con total seguridad si se trataría de un registro que se detenía en el siglo $\mathrm{XIV}$, como los $A I$ o el $L E$, o si por el contrario manifestaría la reutilización de un registro previo adaptado a un contexto del siglo XV, como ocurre con el Cronicón cordubense, ${ }^{29}$ al que parece más cercano.

Las composiciones de las que venimos hablando prueban que, al contrario de lo que tradicionalmente se ha pensado, a lo largo del siglo XIV debieron seguir componiéndose anales, aunque en su mayoría no se hayan conservado. Los testimonios con los que contamos materializan la transmisión y actualización en el área meridional de la Península de un discurso historiográfico, desarrollado en Castilla en las centurias plenomedievales, que narraba lacónicamente la historia castellana entrelazando las noticias referentes a la sucesión de monarcas con las que consignaban enfrentamientos con los musulmanes. Las segundas cumplirían una función legitimadora tanto del poder real como de la

\footnotetext{
${ }^{28}$ Que estos textos viven evoluciones paralelas a partir del trabajo sobre una base común se revela también a través del análisis textual. Así, el texto que publicamos presenta mejores lecturas-o al menos más próximas a las que debían encontrarse en el texto previo-al recoger los topónimos de Girona [9], Galisteo [19], Vejo [27], Tempul [46], Alhabar [48], o en las referencias al día de San Urbán [11], o al de la batalla de las Navas [17], donde la tradición manuscrita de los $A I$ muestra los errores Tripoda, Galicia, Obrero, Tripol, Alfama, san Millán, y cinco días de junio respectivamente [10, 22, 35, 62, 68, 12 y 19]. Por el contrario, los $A I$ ofrecen mejores lecturas o más detalladas en otros topónimos, como Narbona, Iznatorafe, o Alcalá de Guadaira, o al referirse al día de la conquista de Tarifa, como podrá comprobarse en las notas correspondientes a las entradas [9, 20, 40 y 43] de la edición del texto. La tradición manuscrita de los $A I$, que parte de un supuesto libro de Fernán Pérez de Guzmán, se analiza en Benítez y Valdaliso (en prensa). Estos debieron transmitir desde muy pronto los errores que hoy observamos en sus copias modernas.

${ }^{29}$ Cabe recordar el cambio puntual en el sistema de datación justo en el punto en el que empieza a coincidir con estos textos, como elemento que ayuda a evidenciar el trabajo con registros previos.
} 
expansión de sus dominios. ${ }^{30}$ En el siglo XIV a los listados de noticias ordenadas cronológicamente ya existentes se encadenaron referencias a acontecimientos más recientes, relacionados con la frontera y con las ciudades meridionales en las que los reyes permanecían cada vez más tiempo. Por todo ello, representan por escrito-y, en cierto modo, mimetizan-el proceso de expansión de la Corona castellana mientras acompañan su devenir histórico.

Las nuevas redacciones mantienen la esencia del legitimismo neogoticista ya consolidado, pero prestan atención sobre todo a las áreas extremeña y andaluza. Aunque debieron copiarse en algunas ocasiones, frecuentemente se transmitirían reelaborándose, añadiéndose algunas entradas y eliminándose otras. Sucesivos procesos de este tipo habrían dado lugar a diferentes composiciones emparentadas entre sí en mayor o menor grado, de las que serían muestras los AI, el Libro de las eras y, tal vez, el texto que aquí presentamos en la primera mitad del siglo XIV, y el Cronicón cordubense, el Sumario de las cosas que pasaron en los tiempos pasados y los Anales de Garci Sánchez en la centuria siguiente. Estas refundiciones de las primeras décadas del siglo XV se relacionaron, muy probablemente, con las campañas militares contra los musulmanes llevadas a cabo en los reinados de Enrique III y Juan II, y en especial durante la regencia de Fernando de Antequera. Al retomarse esa empresa después llamada Reconquista volvían a estar vigentes aquellas series analísticas en las que una sucesión cronológica de acontecimientos servía de contexto-y base legitimadora-para las acciones del presente.

Creemos que todos estos textos formaban parte de una familia de anales andaluces constituida por un grupo de composiciones interrelacionadas, todas ellas elaboradas entre los reinos de Córdoba y Sevilla en la Baja Edad Media, que materializaban diferentes versiones de un mismo texto cuyo principal argumento fue considerado tan válido en el siglo XV como lo había sido en el XII, aunque las circunstancias fuesen muy diferentes. El peso de estas composiciones como fuentes históricas puede parecer modesto, pues registran muchos hechos ya documentados y frecuentemente lo hacen arrastrando errores de fechas. Su verdadero interés

\footnotetext{
${ }^{30}$ Desarrollamos este tema en un estudio aún no publicado, que lleva por título "Historiografía breve en el siglo de Alfonso X. Composiciones analísticas castellanas en el tránsito de la Plena a la Baja Edad Media (1250-1350)".
} 
reside, en nuestra opinión, en el modo en que transmitían y reformulaban un discurso que a lo largo de varios siglos mantuvo su vigencia. Por ello importa más estudiarlas en conjunto, atendiendo a que cada una de estas manifestaciones nos acerca más y mejor a la hipotética reconstrucción de esa cadena transmisora de la que nos han restado apenas algunos eslabones sueltos. En este sentido, consideramos que el texto que aquí analizamos es una pieza necesaria para la comprensión del todo.

\section{La huella material: el testimonio escurialense Z.III.3}

El texto del que venimos hablando se encuentra en el códice Z.III.3 de la $\mathrm{RBME},{ }^{31}$ un manuscrito en papel compuesto hacia la primera mitad del siglo XV, posiblemente en sus primeras décadas. No se trata de un códice desconocido, pues transmite la Estoria de España de Alfonso X en su versión vulgar (ff. 16r-429v), pero sus folios finales han recibido poca atención. Las descripciones del volumen identifican dos textos: la estoria alfonsí ya mencionada-previa tabla de capítulos-, y unos anales en los folios 430 a 435, constatando la inversión del recto y vuelto del último folio. ${ }^{32}$ No obstante, la estructura de estos folios finales resulta algo más compleja. En el folio 430r, después de la Estoria de España, se inician efectivamente los anales de los que se ocupa este trabajo, que abarcan también el vuelto de este folio, además del recto y vuelto de los folios 433 y 435, este último encuadernado al revés. El folio 431 no contiene los anales, sino un fragmento de la Estoria de España referente al décimo año de reinado de Constantino. También el folio 432 refleja una pieza de la estoria alfonsí, en este caso iniciada con la referencia a Gunderico, rey de los vándalos. Finalmente, el recto del folio 434 presenta otro texto breve

\footnotetext{
${ }^{31}$ Agradecemos a Francisco Bautista que nos diese noticia de la existencia de estos anales y nos facilitase una copia. Sobre el códice véanse Zarco Cuevas (1929, t. 3: 132), Gómez Pérez (1963: 265-266) y Fernández-Ordóńez (2000: 248). El volumen se describe en Philobiblon, BETA manid 1030; sin embargo, allí se sugiere-con dudas-su identificación con los "Anales del toledano romanzado", y consecuentemente se introduce entre los testimonios que transmiten este texto (BETA texid 3702), también conocido como "Anales hasta la conquista de Jaén". Sobre estos véase Catalán (1966). Una edición del texto y un análisis de su relación con el Chronicón cerratense podrá encontrarse en nuestro ya mencionado trabajo en prensa "Historiografía breve en el siglo de Alfonso X. Composiciones analísticas castellanas en el tránsito de la Plena a la Baja Edad Media”.

${ }^{32}$ Fernández-Ordóńez (2000: 248). No observa este aspecto Zarco Cuevas, aunque da cuenta de lo estropeado del manuscrito, y de la falta de folios (1929, t. 3: 132).
} 
independiente que hace un repaso de las edades del mundo, seguido de un apartado final que parece recoger una serie de dichos.

El testimonio presenta dos sistemas de foliación diferentes: el moderno en números arábigos, con cifras a lápiz localizadas en el extremo superior derecho; y uno más antiguo en números romanos, escrito con tinta ocre en el margen inferior derecho. Junto a ellas se observa en algunos folios una tercera numeración también en números romanos. El orden consecutivo que presenta la foliación moderna no responde, como se deduce de lo anterior, a la continuidad lógica de los textos, y tampoco a la foliación-o foliaciones-antiguas:

\begin{tabular}{|c|c|c|c|}
\hline $\begin{array}{l}\text { Foliación } \\
\text { moderna }\end{array}$ & $\begin{array}{l}\text { Foliación } \\
\text { antigua }\end{array}$ & Contenido & Observaciones \\
\hline $429 \mathrm{r}$ & ccccxxiii & Continuación de la Estoria de España & \multirow{2}{*}{$\begin{array}{l}P C G, \text { c. } 429, \text { p. } \\
244 \mathrm{~b} \text { : "de los } \\
\text { suyos, et el fuxo } \\
(\ldots) \text { de las } \\
\text { Espannas". }\end{array}$} \\
\hline $429 \mathrm{v}$ & - & $\begin{array}{l}\text { Continuación del anterior hasta fin de } \\
\text { los ostrogodos }\end{array}$ & \\
\hline $430 \mathrm{r}$ & cccexxvi & $\begin{array}{l}\text { Anales (1) [nota en margen inferior: "fo } \\
2 \text { hojas"] }\end{array}$ & \\
\hline $430 \mathrm{v}$ & - & Anales (2): continuación del anterior & \\
\hline $431 \mathrm{r}$ & ccccxxxix & Décimo año de Constantino, era 356 & \multirow[b]{2}{*}{$\begin{array}{l}\text { PCG, c. 316, p. } \\
\text { 186a-b: } \\
\text { "Constantino } \\
\text { fizo a los } \\
\text { cristianos (...) } \\
\text { paladinamente". }\end{array}$} \\
\hline $431 \mathrm{v}$ & - & Continuación del anterior & \\
\hline $432 \mathrm{r}$ & [rotura] & $\begin{array}{l}\text { Era 453, Gunderico, rey de los } \\
\text { vándalos, etc. }\end{array}$ & \multirow{2}{*}{$\begin{array}{l}P C G, \text { c. } 366, \text { p. } \\
209 \text { b: "En la era } \\
\text { de quatrocientos } \\
\text { (...) todo" }\end{array}$} \\
\hline $432 v$ & - & $\begin{array}{l}\text { Continuación del anterior, fin en } \\
\text { primera columna }\end{array}$ & \\
\hline $433 r$ & ccccvii & Anales (3) & \\
\hline $433 v$ & (iiij) & Anales (4) & \\
\hline $434 \mathrm{r}$ & - & $\begin{array}{l}\text { Texto breve sobre las edades del mundo } \\
\text { y añadido }\end{array}$ & \\
\hline $434 \mathrm{v}$ & \begin{tabular}{l|} 
(ij) $\quad \mid$ \\
¿ccccxxii?
\end{tabular} & En blanco & \\
\hline $435 r$ & \begin{tabular}{ll|} 
(iij) & $\mid$ \\
$\operatorname{ccccxxx}$ &
\end{tabular} & Anales (6) & \\
\hline $435 \mathrm{v}$ & - & Anales (5) & \\
\hline
\end{tabular}


Las vicisitudes que ha vivido el códice, ${ }^{33}$ claramente deteriorado y con folios perdidos, pueden ayudar a entender el desorden de las hojas finales, que debieron integrarse con posterioridad, sin constituir un cuaderno único. ${ }^{34}$ Es muy posible que mostrasen desde entonces estos problemas de organización. Ello afecta no solo a los folios que presentan fragmentos de la Estoria de España o a otros ausentes que servirían para explicar el orden no consecutivo y fragmentario de la foliación antigua, sino también al escrito analístico que nos ocupa, que se interrumpe bruscamente al final del folio 435r, muy probablemente debido a la pérdida de los folios en los que continuaba.

En este conjunto de textos pueden distinguirse diversas manos. Los folios que contienen fragmentos de la Estoria de España presentan una letra tan cercana que podría considerarse la misma, a pesar de algunas diferencias puntuales y del tono variable de la tinta. Otra mano copia el texto sobre las edades del mundo con el añadido final, y una gótica cursiva libraria el de los anales. Cabe notar que en la intitulación de estos se advierte de que se encontraron escritos en un "libro de la disputación de sant Agostín e de sant Bernal” (f. 430r), lo que nos informa de que el modelo de esta copia estaba en un códice cuyo texto principal—que aún no hemos identificado—tenía un carácter teológico o religioso.

En la copia se observan una serie de anotaciones que, más allá de hablarnos de la participación de otra mano-o manos-, muestran claramente varias instancias de intervención. En primer lugar, hay correcciones que afectan a las cifras que encabezan las entradas, y que consisten en la sustitución de alguna letra sobre la propia palabra, por lo que es difícil determinar si las realiza la misma persona que copia el cuerpo de texto, y si lo hace teniendo enfrente el modelo de la copia o cotejando con otro texto. ${ }^{35}$ En lo que respecta a las cifras se observa, además, el añadido sistemático de numeraciones romanas, bien encima o bien al final de la

\footnotetext{
${ }^{33}$ Zarco Cuevas alude, por ejemplo, al incendio de 1671 (1929, t. 3: 132).

${ }^{34}$ En esto incide la nota marginal que habla de un "folio de dos hojas" (f. 430r), o el hecho de que las roturas en cada folio sean manifiestamente distintas, y por lo tanto hablen de una historia previa separada. ${ }^{35}$ Hay varios grupos: la sustitución sistemática de “setecientos” por "seiscientos” en las entradas [5], [6] y [7], y de "setenta” por "sesenta” en las entradas [21], [22] y [24], aunque en realidad esta última corrección debía haberse localizado en la entrada [23] (para más detalles véase la nota correspondiente en edición). La misma corrección se hace en las entradas [50] y [51]. De las correcciones mencionadas, solo estas últimas no concuerdan con las cifras de los paralelos textuales de los anales, y se alejan por lo tanto del modelo.
} 
entrada a la que corresponden. ${ }^{36}$ Estas equivalen puntualmente a la traslación de la era hispánica a números romanos, ${ }^{37}$ pero lo común, y podría decirse que sistemático desde muy pronto a pesar de los errores, es el cálculo del año del nacimiento. ${ }^{38}$ En este sentido, a veces no existe tal correspondencia entre la numeración expresada en el texto y la cifra romana, ${ }^{39}$ pero sí resulta evidente que éstas se incorporaron una vez realizadas las correcciones a las que aludíamos hace apenas un momento. ${ }^{40}$

En el mismo bloque de estas intervenciones relacionadas con la cronología debemos entender también las alusiones a la era de "los Césares" o la era "del dicho César setaena” que encontramos en las primeras entradas, así como la referencia a "del nacimiento", por extenso o de manera abreviada, que vemos junto a algunas cifras. Además de ellas, también encontramos-presumiblemente en la misma letra-ciertos añadidos de texto al final de varias entradas, y acaso a la misma mano se deba también la duplicación de la entrada [25]. Hay otras intervenciones de igual tipo que, sin embargo, se asemejan más a la mano que copia los textos del folio $434 \mathrm{r}^{41}$ A esta misma mano podría tal vez achacarse la indicación "fo dos hojas" en

\footnotetext{
${ }^{36}$ Lo más recurrente es su localización sobre la entrada correspondiente; no obstante, se convierte en norma encontrarlos al final a partir de la entrada [47], en el f. 435r, punto en el que también empiezan a ser casi constantes los errores de cálculo. También se observan algunos casos al final de las primeras entradas, en el f. 430r, donde las cifras también resultan problemáticas.

${ }^{37}$ Por ejemplo, en la entrada [3], donde se traslada la cifra 277, o en la entrada [7].

${ }^{38}$ Los ejemplos se multiplican desde la entrada [9], en el vuelto del folio 430; por ejemplo, en entradas [12], [14], [28], [29]. No obstante, en ocasiones las cifras no coinciden, lo que a veces podemos interpretar fácilmente como errores de cálculo o de escritura. Como se ha dicho, a veces las cifras no coinciden por lo que parecen ser errores de cálculo o escritura, que resultan constantes a partir de la entrada [47], en el f. 435 r.

${ }^{39}$ Ya se han mencionado ejemplos de lo que parecen errores de cálculo, pero hay otros de más difícil explicación. En la entrada [2], que se sitúa en la era 70, se añade "XXXVIII" al final de la entrada, aunque el año resultante debería ser 32 y no 38, ¿quizás se trate de un lapsus por la cifra equivalente a la era hispánica? En la entrada [6] se anota la cifra 655 en romanos, que no equivale ni a la era ni al ańo (658, corregido de 758), y lo mismo en la entrada [7], donde se anota 686 en romanos para 699 (corregido de 799). El caso de la cifra "VI" al final de la entrada [12] debe remitir al día de "sant Leonís" que se menciona justo antes, aunque no coincida con la información de la entrada. De manera muy puntual estas cifras pueden interpretarse como un intento de corregir la cronología del texto, como podrá comprobarse en la edición (véase por ejemplo la entrada [4]). Cabe mencionar que estas cifras tampoco coinciden con la cronología que presentan textos paralelos cuando estos aportan una información divergente.

${ }^{40}$ Parece corroborarlo la entrada [22], donde la cifra romana del año del nacimiento equivale a la cantidad de la era una vez corregida. Lo mismo ocurre en la entrada [21], aunque en ese caso hay un error de cálculo que afecta a las unidades. Sobre la entrada [23], que podría apuntar en el mismo sentido, véase en la edición la nota correspondiente.

${ }^{41}$ Por ejemplo, el término "imperio" al final de la entrada [3], o "que era príncipe de las Asturias" en la [6], ambas en el f. 430r.
} 
el margen inferior del folio 430r, la nota marginal que especifica el nombre de "Martínez de Oviedo" en el f. $435 \mathrm{r},{ }^{42}$ o algunos cambios en la ortografía. ${ }^{43}$ Este conjunto de intervenciones permite pensar en distintas situaciones. Por un lado, un copista (o lector) que corrige la copia teniendo a mano el original, o bien otro texto. Por otro, que se estuviese utilizando la copia como material de trabajo, bien para uso personal-puede que las anotaciones romanas permitiesen una rápida visualización de las fechas de las que trata cada entrada-, o bien para sacar una copia en limpio, corregida, y que tal vez incorporase las dataciones no solo según la era hispánica, sino también por el año del nacimiento, en mayor sintonía con la cronología de las letras que participan en el códice. Una última posibilidad, relacionada con la anterior, sería que este testimonio se estuviese consultando y anotando mientras se preparaba una refundición, tal vez no muy diferente de aquellas que hemos mencionado.

\section{Edición del texto}

\subsection{Criterios de edición y presentación}

A continuación se ofrece el texto de los anales recogidos en el testimonio escurialense Z.III.3, folios 430r-435v, teniendo en cuenta que se ha devuelto el orden natural a los folios que se encuentran desordenados. La foliación moderna se muestra entre corchetes en superíndice. Se numeran las entradas en orden consecutivo, indicándose al inicio de cada una la cifra de la era entre corchetes y la cifra del año entre paréntesis. Se regularizan la presentación gráfica, la puntuación, la acentuación y la unión y separación de palabras según los criterios de Pedro Sánchez-Prieto. ${ }^{44}$ También se desarrollan las abreviaturas sin indicarlo y, cuando es posible, se reconstruye el texto que se ha perdido por la rotura de los folios, indicándolo en cursiva. En nota al pie se apuntan los principales problemas del texto, y se aventuran las lecturas del modelo, pero no se corrigen para no ocultar su posición en

\footnotetext{
${ }^{42}$ Especialmente cercana resulta la última línea del folio $434 \mathrm{r}$.

${ }^{43}$ Por ejemplo, en las entradas [1] y [2], f. 430r, donde se añade "h" a los términos "umana" y "omne", o en la entrada [5] sobre la palabra "Mafomad".

${ }^{44}$ Sánchez-Prieto Borja $(1998,2011)$.
} 
el conglomerado de relaciones de las que forma parte, pues nuestro objetivo principal es entender el texto dentro de su propio proceso de evolución. Igualmente se señalan en nota las intervenciones de la copia que afectan al contenido o suponen un añadido, que tampoco se incorporan al texto editado. No se recogen, sin embargo, las intervenciones eminentemente lingüísticas-por ejemplo, las ortográficas-, las anotaciones derivadas de la traslación de la era a números romanos o de su cálculo en años, o las que solo redundan en el contenido del texto.

\subsection{La edición}

[/430r] En el nonbre de Dios, aquí comienzan los fechos que se fizieron en los tiempos pasados en año, e de cada año su era, de cómo se ganaron los lugares, segund se falló escrito en un libro de la disputación de sant Agostín e de sant Bernal.

1. [38 (0)] En la era de treinta e ocho años vino Jesucristo fijo de Dios en $e l$ mundo, e tomó carne umana de la Virgen bienaventurada señora santa María e nació della, e fincó virgen antes del parto e en el parto e después del parto por siempre. ${ }^{45}$

2. [70 (32)] En la era de setenta años e diez meses e seis días nuestro señor Jesucristo, Dios e omne, fijo de la bienaventurada Virgen santa María, tomó muerte e pasión por nos los pecadores salvar. ${ }^{46}$

3. [277 (239)] En la era de dozientos e setenta e siete años en el tiempo de sant Silvestre, papa, fue Costantino emperador bautizado. E fizo a la Eglesia señora del emperio. ${ }^{47}$

4. [625 (587)] En la era de seiscientos e veinte e cinco años comenzó la seta de los moros e de Mafomad. ${ }^{48}$

${ }^{45}$ La mano dos añade "los césares" en posición supralineal con una llamada triangular entre "de" y "treinta”. A la derecha de esta anotación, con separación, se lee igualmente "otoniano", sin que se observe marca de localización en el texto.

${ }^{46}$ La mano dos añade "del dicho César setaena” sobre la línea. A la derecha, pero separado, se lee "e del", que debe relacionarse con la intención de escribir el año del nacimiento, como es costumbre en la copia.

${ }^{47} \mathrm{La}$ fuente debió constatar la era de 377 años, si tenemos en cuenta el paralelo de los $A I$ [2]. El Cordubense habla de la era de 301 en lo que claramente es un error de la transmisión manuscrita del texto, Lomax (1982: 619 [56]). La tradición establece el bautismo de Constantino en un momento próximo a su muerte, en el año 337, era 375. Falta la lineta de la nasal en el término "señora”.

${ }^{48} \mathrm{La}$ mano que incorpora las numeraciones romanas parece corregir la cronología con dos anotaciones supralineales: "e LX” y “e XXII del nacimiento", y subraya el "cinco años”. Posiblemente también la nota 
5. [750 (712)] En la era de sietecientos e cincuenta años reinó el rey Rodrigo. E duró en su reino siete años e medio, cuando se perdió la tierra fasta las Esturias. $^{49}$

6. [758 (720)] En la era de setecientos e cincuenta e ocho años entraron los moros en España en el tiempo del rey Rodrigo. E en este año alzaron por rey en las Esturias al rey don Pelayo. ${ }^{50}$

7. [799 (761)] En la era de setecientos e noventa e nueve años veno Carlos a Toledo por servir al rey Galafre, cuando llevó a Galiena a París e tornola cristiana e casose con ella. ${ }^{51}$

8. $\left[7^{* *}\left(7^{* *}\right)\right] \quad{ }^{[/ 430 v]}$ En la era de setecientos [en blanco] fizo Adurhames la mezquita de Córdova. E fue fecha de los averes que los moros ganaron de los cristianos. $^{52}$

9. [829(791)] En la era de ochocientos e veinte nueve años fizo Ozim, fijo de Adurahamed, la puente de Córdova de los averes que ganó cuando presó a Navara e Girona. ${ }^{53}$

10. [970 (922)] En la era de nuevecientos e setenta años comenzó la orden de Santiago en el tiempo del rey Ramiro.

11. [1112 (1074)] En la era de mill e ciento e doze años fue tomada Toledo en el día de sant Urban. ${ }^{54}$

"DC" que aparece bajo la entrada sirva en este caso para completar la corrección, pues hay una marca de llamada. El resultado final podría interpretarse como "En la era de seicientos e LX e (veinte) DC e XXII del nascimiento". Como se observa, quedó sin cancelar el veinte escrito, que se encontraría duplicado. No obstante, tanto los $A I$ como el Cordubense aportan la misma datación que el texto base para esta entrada, $A I$ [4] y Lomax (1982: 619 [57]).

${ }^{49} \mathrm{El}$ "sietecientos" está corregido por "seiscientos", siendo la corrección la que coincide con la lectura de los $A I$ [5]. El Cordubense señala aquí la era de 758, Lomax (1982: 619 [58]). Falta la lineta la segunda vez que se lee "años".

${ }^{50} \mathrm{Al}$ igual que en la entrada anterior, "setecientos" está corregido por "seiscientos". También aquí la corrección nos acerca a los $A I$, que constatan la era de 758, $A I$ [6]. El Cordubense registra la era de 759, Lomax (1982: 619 [59]). Otra mano añade "que era príncipe de Asturias" al final.

${ }^{51}$ De nuevo se ha corregido "setecientos" por "seiscientos". La cifra difiere en los $A I$, que registran la era de $790[8]$.

${ }^{52}$ Ninguno de los textos paralelos aporta una cifra que comience por siete para deducir el contenido que se dejó en blanco: los $A I$ presentan la era de 825 [9], mientras que el Cordubense habla del año de 801, Lomax (1982: 619 [61]).

${ }^{53}$ La lectura del modelo, o de alguno de sus antecedentes-al menos de la fuente-, fue sin duda "Narbona" en lugar de Navara, como constatan los $A I$ [10], apoyados a su vez por otros textos narrativos; por ejemplo, la Estoria de los árabes, traducción de la Historia Arabum realizada en el siglo XIV, Bravo López (2019: 305) o la Estoria de España; por ejemplo, E2, c. 621, f. 16r, en Ward (2016).

${ }^{54}$ La palabra ha sido intervenida por la mano que realiza las correcciones, detectándose las formas "Urban" y "Urbano". 


\section{Carmen Benítez Guerrero \& Covadonga Valdaliso Casanova}

12. [1132 (1094)] En la era de mill e ciento e treinta e dos años prisó el Cid Ruy Díaz a Valencia en el día de sant Leonís. ${ }^{55}$

13. [1157 (1119)] En la era de mill e ciento e cincuenta e siete años morió el Cid Ruy Díaz en Valencia.

14. [1232(1194)] En la era de mill e dozientos e treinta e dos años fue la batalla de Alarcos en el mes de jullio, e fue vencido el rey don Alfonso e todos los cristianos que eran con él.

15. [1234(1196)] En la era de mill e dozientos e treinta e cuatro años fue poblada Palencia del rey don Alfonso, nieto del emperador de España, en el día de santa María de agosto. ${ }^{56}$

16. [1235 (1197)] En la era de mill e dozientos e treinta e cinco años fue presa Vitoria. ${ }^{57}$

17. [1250 (1212)] En la era de mill e dozientos e cincuenta años fue la batalla de las Naos de Tolosa en diez e seis días de jullio, cuando fueron vencidos los moros. E en esta fue presa Ulda e Bilchis $e$ Baños. ${ }^{58}$

18. [1252 (1214)] ${ }^{[/ 433 r]}$ En la era de mill e dozientos e cincuenta e dos años morió el rey don Alfonso en Ávila en el mes de otubre ${ }^{59}$. En este año ovo grand fambre en Castilla.

19. [1255 (1217)] En la era de mill e dozientos e cincuenta e cinco años fue poblada Galisteo. $^{60}$

20. [1257 (1219)] En la era de mill e dozientos e cincuenta e siete años presó el rey don Ferrando a Andújar, e a Salvatierra, e a Egaetaf. ${ }^{61}$

21. [1275 (1237)] En la era de mill e dozientos e setenta e cinco años fue presa Baeza en la fiesta de sant Andrés. ${ }^{62}$

\footnotetext{
${ }^{55}$ Se añade "VI" al final de la entrada, lo que quizás corresponda al día de san Leonardo que se celebra el 6 de noviembre, de cualquier modo alejado del día de conquista de Valencia, a mediados de junio.

${ }^{56}$ Se refiere a Plasencia, como constata el Cordubense, Lomax (1982: 621 [75]). Se trata de un error frecuente, como podrá observarse en entradas posteriores e igualmente recurrente en la tradición manuscrita de los $A I$ [17], [28], [29] y [41].

${ }^{57}$ La segunda mano añade "que la tomó este rey don Alfonso".

${ }^{58}$ La segunda mano añade "por el rey don Alfonsso de Castilla" al final de la entrada. Una nota marginal debe consignar lo mismo, aunque resulta difícil de leer. Se refiere a Úbeda, como constatan el Libro de las Eras, RBME, X.II.12, f. 103v y el Cordubense, Lomax (1982: 622 [78]). Ambos textos permiten igualmente reconstruir el término "fueron", que falta debido a la rotura del folio.

${ }^{59}$ Otra mano añade "e regnó su fijo don Fernando" a partir de un signo de llamada.

${ }^{60}$ Se añade "que la pobló el rey don Fernando" al final de la entrada.

${ }^{61}$ Se refiere a Iznatoraf, según constatan los $A I$ [23]. Presenta la variante "Aznatoraf" la edición del Cordubense, Lomax (1982: 623 [82]).

${ }^{62}$ El término "setenta" está corregido por "sesenta", acercándose así a los $A I$ [24], al $L E$, RBME, X.II.12, f. 104r, y al Cordubense, aunque éste sitúa la entrada en otra localización, Lomax (1982: 626 [89]). También está corregido el término "fiesta" tachando la -r- de "firesta".
} 
22. [1276 (1238)] En la era de mill e dozientos e setenta e seis años el maestre de la orden de Santiago con sus frailes tomó a Montiel e venció a Abehamud en el campo. ${ }^{63}$

23. [1277 (1239)] En la era de mill e dozientos e setenta e siete años el rey don Alfonso de León lidió con Abenhamud e venciólo. E en este tiempo tomó a Montanches, e a Mévida, ${ }^{64}$ e a Badajos.

24. [1271 (1233)] En la era de mill e dozientos e setenta e un años fue presa otra vegada Úbeda. ${ }^{65}$ E en esta ora el obispo de Palencia con el concejo dél e con los cavalleros de las órdenes presieron a Trogillo en el mes $\mathrm{d} e$ enero, en la fiesta de la conversión de sant Pablo.

25. [1272 (1234)] En la era de mill e dozientos e setenta e dos años Rodrigo Paues, comendador de Monteanches, e el obispo de Palencia, e el maestre de Alcántara, presieron a Medelín. ${ }^{66}$ En este año el concejo de Trugillo presó a Santa Cruz. E en este año morió el rey don Sancho de Navarra. ${ }^{67}$

${ }^{63}$ También aquí se corrige de "setenta” a "sesenta". La corrección nos acerca a los $A I$, aunque aquéllos hablan de la era de 1262 [25], lo que debe tratarse de un error pues rompe la sucesión cronológica del texto. El Cordubense habla del año de 1229, que equivaldría a la era de 1267. Según constata Lomax, esta cronología debe ser la correcta, y está presente también en la lista de jueces del Fuero de Cuenca, Lomax (1982: 624, [84] y nota 66). Se corrige también "en el canpo", mediante subrayado y añadiendo "rey de Granada en el canpo" al final de la entrada, aparentemente por la segunda mano. "Campo" parece entenderse como un topónimo en los $A I$ [25] y en el Cordubense, Lomax (1982: 624 [84]). También se ha añadido "e cavalleros” sobre el renglón, detrás de "frailes”, sin que quede tan claro si se trata de la mano que copia el texto o la que realiza las intervenciones, por lo que no se incorpora a la edición.

${ }^{64}$ La errata del texto se encuentra corregida sobre el renglón por la mano dos, que añade la r sobre la v.

${ }^{65}$ En este caso también aparece corregido "setenta” por "sesenta"; no obstante, la corrección es errónea tanto en relación con los paralelos textuales—AI [27] y Cordubense, Lomax (1982: 625 [87])—, como en cuanto al orden cronológico del texto. Parece probable que esta corrección estuviese destinado a la entrada anterior, donde sí coincidiría con sus paralelos. Además, serviría para explicar el cálculo del año del nacimiento añadido sobre aquélla, que se realiza sobre 1267 y no sobre 1277 . También está corregido el término "un" sobre lo que parecía ser "VIII". E igualmente se corrige "Palencia” por "Plalencia", posiblemente por otra mano, acercándose así a la lectura correcta, ver $A I$ [28]. En el mismo sentido, el término "ora” debía ser "era".

${ }^{66}$ En este caso ocurre lo mismo que en la entrada anterior para el término "Palencia". El comendador de Montánchez es Rodrigo Yáñez, según informa Lomax a partir de documento sobre la conquista fechado en 26 de marzo de 1235, al anotar al Cordubense, Lomax (1982: 625-626, nota 72). El texto del Cordubense, sin embargo, no menciona al comendador, aunque recoge la conquista de Medellín. Sí aparece Rodrigo Íñiguez en los $A I$ [29].

${ }^{67}$ Otra mano añade a continuación una entrada equivalente: "En la era de mill e trecientos diez del nacimiento, etcetera. El obispo de Placencia e el mestre de Alcántara e Rodrigo Panos, comendador de Montanches, tomaron a Medelim. En este año mesmo el concejo de Trugillo tomaron a Santa Cruz. E en este [año] morió el rey don Sancho de Nauarra”. La entrada resulta de añadir en limpio algunas correcciones realizadas sobre la anterior, concretamente un cambio de orden marcado a través de marcas de llamada. También se ha calculado erróneamente el año del nacimiento, pues en lugar de restarse se han sumado 38 años a la era. 


\section{Carmen Benítez Guerrero \& Covadonga Valdaliso Casanova}

26. [1274 (1236) $]^{[/ 433 v]}$ En la era de mill e dozientos e setenta e cuatro años fue tomada Córdova, en la fiesta de sant Pedro e de sant Pablo. ${ }^{68}$

27. [1274 (1236)] En la era de mill e dozientos e setenta e cuatro años escureció el sol. E prisieron los moros a Jerusalem. E en este año pressó el concejo de Córdova a Vejo. ${ }^{69}$

28. [1278(1240)] En la era de mill e dozientos e setenta e ocho años presó el rey don Ferrando a Almodóvar, e a Moratilla, e a Fornachuelos, e Alcolea, e Alcocer, e a Montoro, e a Castro.

29. [1279 (1241)] En la era de mill e dozientos e setenta e nueve años presó el rey don Ferrando a Baena, e a Luque, e a Osuna, e a Palma, e a Marchena.

30. [1280 (1242)] En la era de mill e dozientos e ochenta años pressó el infante don Alfonso, fijo del rey don Fernando, a Chinchilla e a las Peñas de sant Pedro.

31. [1281 (1243)] En la era de mill e dozientos e ochenta e un años pressó el infante don Alfonso a Murcia.

32. [1284 (1246)] En la era de mill e dozientos e ochenta e cuatro años pressó el rey don Ferrando a Jaén.

33. [1285 (1247)] En la era de mill e dozientos e ochenta e cinco años pressó el rey don Ferrando a Cantillana e a Jerena. E en este año el infante don Enrrique pressó a Ructe e a Morón. E en este año el prior del Ospital con el obispo e el concejo de Palencia e de Trugillo e de Cacres pressieron a Lora. $^{70}$

34. [1286 (1248)] En la era de mill e dozientos e ochenta e seis años pressó el rey don Ferrando Aznalfarache, e Alcalá del Río, e a Santlúcar la Mayor, e a Sufre. E en este año el infante don Enrrique pressó a Xerez, e a Cáliz, e a Arcos.

35. [1287 (1249) $]^{[/ 435 v]}$ En la era de mill e dozientos e ochenta e siete años fue pressa la ¿muy? noble cibdat de Sevilla, e ganóla el noble rey don Ferrando en la fiesta de sant Clemente.

\footnotetext{
${ }^{68}$ Otra mano añade "por el rey don Fernando" al final de la entrada.

${ }^{69}$ Se refiere a la conquista de Ovejo, Cordubense, Lomax (1982: 626 [89]. También la recogen los AI, aunque toda la tradición manuscrita de este texto redunda en el error "Obrero" [35].

${ }^{70}$ De nuevo se corrige Palencia por "Plalencia” en esta entrada, acercándose a la lectura correcta, Plasencia. Las diferencias con los $A I$ en la toponimia-que también recoge esta entrada, aunque separada en dos-, muestran el resultado del proceso de transmisión y la intervención de copistas que claramente encontraron dificultades para entender los nombres, en ambos casos. Así, los AI hablan de "Santillana y Jamillena", de "Cortes y Morón", e igualmente de "Palencia" en algunos testimonios. "Cacres" deriva claramente de "Cáceres”, como también encontramos en algún testimonio de los $A I$, donde el término muestra su propia evolución [40].
} 
36. [1290 (1252)] En la era de mill dozientos e noventa años morió el rey don Ferrando, en el postrimero día de mayo. ${ }^{71}$

37. [1297 (1259)] En la era de mill e dozientos e noventa e siete años fue el año de las muchas aguas.

38. [1299 (1261)] En la era de mill e dozientos e noventa e nueve años fue pressa Niebla e Gibraleón e Huelna. ${ }^{72}$

39. [1302 (1264)] En la era de mill e trezientos e dos años quebrantaron los moros las pazes e bolviéronse las guerras. ${ }^{73}$

40. [1305 (1267)] En la era de mill e trezientos e cinco años fue otra vez pressa Xerez, e Alcalá, e Medina, e Leger el día de sant Deonís. ${ }^{74}$

41. [1313 (1275)] En la era de mill e trezientos e treze años murió el infante don Ferrando de la Cerda, en treze días de jullio. ${ }^{75}$ E en aquel año mataron los moros a don Nuño en Écija, en siete días de setiembre.

42. [1322 (1284)] En la era de mill e trezientos e veinte e dos años murió el infante don Alfonso, a cuatro días de abril.

43. [1330 (1292)] En la era de mill e trezientos e treinta años pressó el rey don Sancho a Tarifa, en el día de sant Marcos. ${ }^{76}$

44. [1333 (1295)] En la era de mill e trezientos e treinta e tres años finó el rrey don Sancho a veinte días de abril, e reinó su fijo el rey don Ferrando. ${ }^{77}$

45. [1337 (1299)] En la era de mill e trezientos e treinta e siete años cercó el rey don Ferrando a Algezira e ganó a Gibraltar.

46. [1348 (1310)] ${ }^{[/ 435 r]}$ En la era de mill e trezientos e cuarenta e ocho años ganó el rey don Ferrando a Quesada e a Betmar con sus castillos. E en este año ganó el infante don Pedro a Tempul.

\footnotetext{
${ }^{71}$ Otra mano añade “e rengnó [sic] su fijo el rey don Sancho”.

${ }^{72}$ Se observa una confusión de la grafía u por n, copiándose erróneamente "Huelva”.

${ }^{73}$ Otra mano añade "con los christianos".

${ }^{74}$ Se refiere a Vejer, como atestigua el Cordubense, Lomax (1982: 628 [100]). Tampoco aciertan en la toponimia los $A I$, que leen "Vega" [51], aunque se aproxima en mayor medida a la lectura original.

${ }^{75}$ El término "días” aparece duplicado y corregido mediante subrayado.

${ }^{76}$ Se trata del día de san Mateo, como debió consignar algún momento anterior del texto. Así lo atestiguan los $A I$ [57], el LE, RBME, X.II.12, f. 104v, y el Cordubense, Lomax (1982: 629 [104]). También lo recoge la crónica del monarca, Saracino (2014: 157).

${ }^{77}$ Debe suponerse que un estado anterior del texto recogió una cifra más cercana al verdadero día de la muerte del rey. Los $A I$ hablan del día 27 [58], mientras el $L E$ dice que fue "cinco días por andar de abril", RBME, X.II.12, f. 104v. La Crónica de Sancho IV menciona el día 25 después de medianoche, Saracino (2014: 185), y la de Fernando IV considera que el reinado del sucesor comenzó en miércoles 26 de abril, Benítez (2017: 9).
} 


\section{Carmen Benítez Guerrero \& Covadonga Valdaliso Casanova}

47. [1350 (1312)] En la era de mill e trezientos e cincuenta años ganó el rey don Ferrnando a Alcabdete a dos días de setiembre. Ítem en este mesmo mes finó este rey don Ferrando, en seis días del dicho mes. ${ }^{78}$

48. [1357 (1319)] En la era de mill e trezientos e cinquenta e siete años ganó el infante don Pedro e el infante don Juan, su tío, a Alhabar e a Cambil. E desta entraron en la Vega de Granada e mataronlos allá a amos a dos los moros, en lunes, a veinte e cinco días de jullio, otro día de sant Juan.

49. [1377(1339)] En la era de mill e trezientos e setenta e siete años don Gonzalo Martines, ${ }^{79}$ maestre de Alcántara, e cavalleros de Castilla, e el concejo de la muy noble cibdat de Sevilla, mataron al infante Picazo, fijo del rey Albohacén de Benamarín, e otros muchos moros, en un logar que dizen Petrite e Alujte, allende legua e media de Alcalá de los Gazules.

50. [1378 (1340)] En la era de mill e trezientos e setenta e ocho años, ${ }^{80}$ en lunes veinte e ocho días de otubre, venció el rey don Alfonso de Castilla, e el rey de Portogal que le vino ayudar, al rey de Albochacén de Benamarín, e al rey de Túnez, e al rey de Bugia, e a don Yucaf, ${ }^{81}$ rey de Granada, cerca de Tarifa, que la tenían cercada. E morieron aý muchos cavalleros de moros, e muchos peones, e las reinas moras, e otras muchas moras con ellas. E fue preso Boamar, el infante fijo del rey de Benamarín.

51. [1375 (1337)] En la era de mill e trezientos e setenta e cinco años morió el infante don Felipe, a doze días de abril. E vino el rey don Alfonso en el mes de mayo, e entró en Sevilla a cuatro días del dicho mes. ${ }^{82}$

\footnotetext{
${ }^{78}$ También en esta entrada encontramos divergencias en los días con respecto a otros paralelos analísticos. La conquista de Alcaudete se sitúa el 7 de septiembre en el $L E$, y el día de santa María de septiembre en el Cordubense, esto es, el 8, sin que aporten una cifra los $A I$. Por su parte, la muerte del monarca aparece el 7 de septiembre, víspera de santa María, en los $A I$ y el 8 en el $L E$, mientras que no da una cifra el Cordubense, ver $A I$ [63] y [64], LE, RBME, X.II.12, f. 105r, y Lomax (1982: 630 [109]). La crónica del monarca localiza la conquista de Alcaudete-llevada a cabo por el infante don Pedro y no por el monarca, como manifiestan también los $A I$-, en 5 de septiembre, y la muerte del rey, coincidiendo también con estos últimos, en 7 de septiembre, víspera de santa María, Benítez (2017: 167). Cabe mencionar, no obstante, que algunos testimonios de la crónica-DFG-establecen la conquista en el día 4, Benítez (2017: cd, 385). ${ }^{79}$ Se observa que una mano ha intervenido para corregir "setenta" por "sesenta”. El $L E$ apoya la cifra “setenta”, RBME, X.II.12, f. 106r. El Cordubense habla del año de 1345, lo que equivaldría a la era de 1383. En ambos casos las entradas coinciden en la noticia de la que se está informando, pero no son textualmente idénticas.

${ }^{80}$ Encontramos la misma situación que en la entrada previa con respecto a la cifra "setenta".

${ }^{81}$ Se ha olvidado el trazo de la cedilla.

${ }^{82}$ Debería ser 1327, concretamente el 12 de abril. Lo mismo ocurre con la siguiente entrada, que por lo tanto debería fecharse en la era de 1365. Así se observa en el Cordubense, Lomax (1982: 631 [113]), que consecuentemente sitúa esta entrada inmediatamente después del desastre de la Vega de Granada, donde habían concluido los $A I$ y aquí en entrada [48]. El $L E$ solo habla de la venida de Alfonso XI a Sevilla para esta era, sin mencionar día ni dar noticia sobre la muerte del infante, $L E$, RBME, X.II.12, 105 r.
} 
52. [1376(1338)] En la era de mill e trezientos e setenta e seis años ganó el rey don Alfonso a Olvera, a cinco días del mes de junio, e a la Torre. ${ }^{83}$

\author{
Carmen Benítez Guerrero \\ https://orcid.org/0000-0001-9610-9024 \\ Universidad de Sevilla \\ cbenitez@us.es
}

Covadonga Valdaliso Casanova

https://orcid.org/0000-0002-9825-1574

Centro de História da Universidade de Lisboa I

Universidad de Alcalá de Henares

cCasanova@letras.ulisboa.pt

\footnotetext{
${ }^{83}$ Como se ha explicado en el estudio, la entrada se encuentra truncada. Pueden ayudarnos a deducir el contenido de la misma los paralelismos en el $L E$ : "En el mes de junio siguiente ganó a Olvera de moros, e a Pruna, e la Torre de l'Alfasmi. E vino a Sevilla dos días por andar de jullio" (RBME, X.II.12, f.105v). El Cordubense presenta esta información unida a la de la entrada anterior: “(...) En este anno gano el rrey don Alfonso a Oluera e a la Torre de Alaquem e Ayamonte, e gano a Pruna e entrola por fuerça vigilia de Santiago", Lomax (1982: 631 [113]). Como se ha dicho, la localiza inmediatamente después del desastre de la Vega de Granada, mientras que el $L E$-que antes solo consignó la información sobre la ida de Alfonso XI a Sevilla_, intercala entre ambas la noticia sobre la muerte de Juan el Tuerto.
} 


\section{Bibliografía}

Bautista, F. (2020), "De nuevo sobre el Libro de las generaciones y linajes de los reyes (o Liber regum): recuperación de la versión toledana de hacia 1219”, e-Spania [URL: $<$ http://journals.openedition.org/e-spania/37546> (31/10/2021)].

Benítez Guerrero, C. (ed.) (2017), Crónica de Fernando IV. Estudio y edición de un texto postalfonsi, Sevilla/El Puerto de Santa María: Universidad de Sevilla y Cátedra Alfonso $\mathrm{X}$ el Sabio.

Benítez Guerrero, C. y Valdaliso Casanova, C. (en prensa), "Los Anales del infante: un registro analístico inédito del reinado de Alfonso XI”, Intus Legere.

Bravo López, F. (ed.) (2019), Estoria de los árabes. Traducción castellana del siglo XIV de la Historia Arabum, Córdoba: UCOPress.

Catalán, D. (1966), "El Toledano romanzado y las Estorias del fecho de los Godos", Estudios dedicados a James Homer Herriott, Madison: Universidad de Wisconsin, pp. 9-102.

Fernández-Ordóñez, I. (2000), "La transmisión textual de la Estoria de España y de las principales crónicas de ella derivadas”, en Alfonso X y las crónicas de España, Valladolid: Universidad de Valladolid, pp. 219-260.

Gómez Pérez, J. (1963), "Elaboración de la Primera Crónica General de España y su transmisión manuscrita”, Scriptorium 17/2: 233-276.

Jiménez López, J. (2021), "Dos manuscritos en busca de autor: Pedro de Toledo, copista e iluminador en Sevilla”, Materia 18-19: 63-83.

Lahoz Gutiérrez, M. L. (2015), "Patronato, gusto y devoción del Arzobispo Anaya”, en M. L. Lahoz, M. Pérez (coords.), Lienzos del recuerdo: estudios en homenaje a José Ma Martinez Frias, Salamanca: Ediciones Universidad de Salamanca, pp. 291-300.

Lomax, D. (1978), "Una nueva obra andaluza: la Crónica de Fernando de Salmerón” en Andalucia medieval. Actas del I Congreso de Historia de Andalucia, Tomo I, Córdoba: Caja Sur, pp. 271-273.

(1982), "El Cronicón Cordubense de Fernando de Salmerón”, En la España medieval 2: 595-642.

Menéndez Pidal, R. (1898), Crónicas generales de España. Catálogo de la Real Biblioteca. Manuscritos, Madrid: Sucesores de Ribadeneyra.

(1918), Crónicas generales de España. Catálogo de la Real Biblioteca, T. V. Manuscritos, 3 a ed., Madrid: Blass y Cía.

Nieto Soria, J. M. (2006), Un crimen en la corte. Caida y ascenso de Gutierre Álvarez de Toledo, señor de Alba (1376-1446), Madrid: Sílex.

Roxas y Contreras, J. (1770), Historia del Colegio Viejo de San Bartholomé, mayor de la célebre Universidad de Salamanca, Tomo tercero, Madrid: Antonio Ortega.

Sánchez-Prieto Borja, P. (1998), Cómo editar los textos medievales. Criterios para su presentación gráfica, Madrid: Arco Libros.

(2011), La edición de textos españoles medievales y clásicos. Criterios de presentación gráfica, San Millán de La Cogolla: Cilengua.

Saracino, P. E. (ed.) (2014), Crónica de Sancho IV, Buenos Aires: Incipit.

Satorre Grau, J.J. (1980), "La novela moral de Graçián (Un texto inédito del siglo XV)”, Estudios Lulianos. Revista de Investigación Luliana y Medievalistica 24.71: 165-210. 
Valdaliso Casanova, C. (2021), "Los Anales de Garci Sánchez: un registro historiográfico de un autor converso" en Los trastámara en Castilla y Aragón: el papel de las minorias (siglos XIV al XVI) (R. Amrán y A. Cortijo Ocaña coord.), Madrid: Pórtico, pp. 185-212.

Vázquez Janeiro, I. (1996), "Los estudios franciscanos medievales en España” en VI Semana de Estudios Medievales: Nájera, 31 de julio al 4 de agosto de 1995 (J.I. de la Iglesia Duarte, F.J. García Turza, J.A. García de Cortázar coord.), Logroño: Instituto de Estudios Riojanos, pp. 43-64.

Ward, A. (ed.) (2016), Estoria de Espanna Digital v.1.0, Birmingham: University of Birmingham [URL: <estoria.bham.ac.uk/edition> (20/09/2021)].

Zarco Cuevas, J. (1929), Catálogo de los manuscritos castellanos de la Real Biblioteca de El Escorial, Madrid:s. n. 